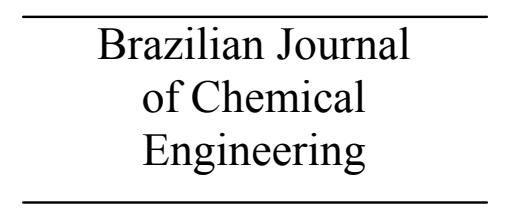

ISSN 0104-6632

Printed in Brazil

www.abeq.org.br/bjche

Vol. 26, No. 01, pp. 181 - 188, January - March, 2009

\title{
HIGROSCOPIC PROPERTIES OF CASTOR SEEDS (Ricinus Comunis L.)
}

\author{
M. C. Gely ${ }^{*}$ and E. M. Santalla \\ Faculty of Engineering, Universidad Nacional del Centro de la Provincia de Buenos Aires, \\ Seeds Technology Program TECSE, \\ Av. Del Valle 5737, B7400 JWI, Olavaria, Argentina. \\ E-mail: cgely@fio.unicen.edu.ar
}

(Submitted: May 8, 2008 ; Accepted: July 17, 2008)

\begin{abstract}
Sorption isotherms of castor seeds were evaluated at 30, 40, 50 and $60^{\circ} \mathrm{C}$ using the static gravimetric method. Sigmoid trends were observed for isotherms obtained showing a clear effect of temperature. Experimental values were adjusted using the modified isotherms of Henderson, Halsey, Oswin and Guggenheim-Anderson-de Boer (GAB). Models were compared using four statistics parameters. The results showed that Modified Henderson model adjusted adequately the experimental values in the range of temperature evaluated. The experimental values of the safe storage moisture content for castor seeds varied between 6.1 to $8.4 \%$ (d.b.) between 20 and $40^{\circ} \mathrm{C}$, showing lower values than those reported for other traditional oilseeds as sunflower or rapeseed. The sorption heats evaluated from the combination of Clapeyron equation and Modified Henderson equation varied between 3400 and $2373 \mathrm{~kJ} / \mathrm{kg}$ for moisture contents between 1 and $28 \%$ (d.b.). Through Othmer relationship the value of the ratio $\mathrm{L}_{\mathrm{b}} / \mathrm{L}_{\mathrm{f}}$ varied between 1.01 and 1.34 (for 14.5 and $1 \%$ d.b. moisture content respectively). The values obtained showed an exponential relationship with moisture content, of the form $\mathrm{L}_{\mathrm{b}} / \mathrm{L}_{\mathrm{f}}=1+0.44 \exp (-0.17 \mathrm{M})$ with a determination coefficient $\mathrm{R}^{2}$ of 0.97 .
\end{abstract}

Keywords: Castor seeds; Isotherms; Equilibrium moisture content.

\section{INTRODUCTION}

Castor (Ricinus comunis) culture grows in warm regions of north Argentina and Brazil. The high content of ricinoleic acid in the oil (higher than $85 \%$ ) indicates that it is not apt for human consumption. Due to its physical and chemical properties the oil is used as raw material for several industrial applications and for the production of biofuels. The resistance of the culture to dough conditions gives an additional opportunity to increase its exploitation in marginal regions, promoting also the developing of regional economies without competition with traditional oilseeds (Falasca et al., 2006).

There is a lack of information about the behavior of these oilseeds during post-harvest stages, mainly storage and drying processes. The current situation in
Argentine is the culture of the seed in a manual way and storage in silos until oil extraction.

Equilibrium moisture content $\left(\mathrm{M}_{\mathrm{e}}\right)$ and equilibrium relative humidity $(\mathrm{ERH})$ relationships are essential factors in the design of the drying and storing processes. To determine safe moisture values where microbial growth can be prevented, is a useful tool. The equilibrium moisture content of the grain at different relative humidity and temperature is also helpful for calculating the heat of vaporization, which is an important thermodynamic grain property. This property, defined as the energy required to vaporize the water from the grain at different conditions, showed marked differences between grains (Brooker et al., 1992) and constitutes one of the key factors in the design of the drying equipment.

*To whom correspondence should be addressed 
Rao and Rizvi (1994) demonstrated that at equilibrium conditions, the relative humidity equals to water activity of the grain. Therefore an equation that could describe the relationship between water activity $\left(\mathrm{a}_{\mathrm{w}}\right)$, equilibrium moisture content $\left(\mathrm{M}_{\mathrm{e}}\right)$ and temperature $(\mathrm{T})$ would be an useful tool for the simulation of agricultural product during postharvest processes. Many theoretical, semi-theoretical and empirical isotherm equations have been developed for modeling the water sorption behavior of many grains (Chen and Jayas, 1998). However it is always desirable to find both, a justification using the physico-chemical phenomena for a sorption equation and a simple theoretical equation that describes accurately the experimental sorption data (Shatadal and Jayas, 1990). A sorption isotherm with temperature dependent parameters would be a helpful tool to predict the equilibrium moisture content for different drying process conditions.

Chirife and Iglesias (1978) found that each model has some success in the prediction of equilibrium moisture data for a product under determined moisture and temperature conditions. Therefore the selection of the most adequate moisture sorption isotherm equation for each grain in a range of relative humidity and temperature is relevant. On the other hand, the heat of sorption is an estimation of the minimum amount of heat required for removing a given amount of water and it also allows some deduction about the grain micro-structure and the physical changes occurring on the grain surface. One method widely used to calculate the heat of sorption $\left(\mathrm{L}_{b}\right)$ of many foods is based on the ClausiusClapeyron equation, which assumes temperatureindependent heat of sorption and allows a simple calculation of the isosteric heat from the sorption. An alternative method for calculating isosteric heats developed by Othmer (Perry and Chilton, 1991) assumes that the heats of both sorption and condensation have the same temperature dependence. This assumption is less restrictive than the Clapeyron method, in which both heats are considered to be constant (Aguerre et al., 1988).

The objectives of this work are to know the behavior of equilibrium moisture content of castor seeds in the temperature range that usually is applied in post-harvest process, to evaluate an isotherm model that could predict equilibrium values at different temperatures and to estimate the heat of sorption of water of castor seeds.

\section{MATERIALS AND METHODS}

Castor seeds IAC-Guaraní variety, harvested at Misiones, Argentina (WL $27^{\circ} 19^{\prime} \mathrm{SL} 55^{\circ}$ 53) during year 2005 were used. The seeds were stored at $5^{\circ} \mathrm{C}$ after harvest and before utilization.

The seeds were manually cleaned to eliminate strange, immature and crashed materials. Moisture content was determined according AOAC 14.003 method (AOAC, 1980), under vacuum, $100^{\circ} \mathrm{C}, 8 \mathrm{~h}$ or until constant weight. Oil content was determined by solvent extraction according to the American Oil Chemist's Society (AOCS, 1997), Ae 3-52 method. All determinations were carried out by triplicate.

Equilibrium moisture content of castor seeds was experimentally determined through static gravimetric method using saturated solutions at different concentrations in order to maintain constant relative humidity. Seven values for the relative humidity were used, varying between 11 and $80 \%$ at 30, 40, 50 and $60^{\circ} \mathrm{C}$. Castor seeds were wetted over their equilibrium values in order to assure the desorption process. After wetting, samples were kept during three days to allow homogenization of moisture in the core of the grains. Approximately $10 \mathrm{~g}$ of seeds were kept in desiccators under saturated saline solutions of known relative humidity. Phenol was used in higher relative humidity containers, in order to avoid the fungi development during testing. Samples into desiccators were kept under controlled atmosphere $\left( \pm 1^{\circ} \mathrm{C}\right)$ allowing all samples to equilibrate until weight changes lower than $\pm 0.001 \mathrm{~g}$. The time to reach equilibrium varied between samples but it was approximately three weeks. Finally, equilibrium moisture content was determined according AOAC 14.003 method. The samples that deviated more than $0.6 \%$ from the mean of triplicates were eliminated.

According to recommendations of ASAE standard (ASAE, 1999), four equations were selected for the adjusting of experimental data of $\mathrm{M}_{\mathrm{e}} / \mathrm{a}_{\mathrm{w}}$ (Chen and Morey, 1989). The equations used were Modified Henderson (Eq. 1), Modified Halsey (Eq. 2), Modified Oswin (Eq. 3) and GuggenheimAnderson-de Boer (GAB) equation (Eq. 4). Equations (1), (2) and (3) are temperature-dependent while the GAB isotherm (Eq. 4), one the most satisfactory theoretical equations, has its parameters dependent with temperature (Shatadal and Jayas, 1990) which can be explicitly resolved for $a_{w}$ and $M_{e}$. Sun (1999) has reported that equations with three parameters (A, B and C) will give better adjustments of equilibrium data than equations with more parameters.

$$
M_{e}=\left(\frac{\ln \left(1-a_{w}\right)}{(-A(T+C))}\right)^{(1 / B)}
$$




$$
\begin{aligned}
& M_{e}=\left(\frac{\ln \left(a_{w}\right)}{-\exp (A+B T)}\right)^{C} \\
& M_{e}=(A+B T)\left(\frac{a_{w}}{1-a_{w}}\right)^{C} \\
& M_{e}=\frac{A B C a_{w}}{\left(1-B a_{w}\right)\left(1-B a_{w}+B C a_{w}\right)}
\end{aligned}
$$

Systat Statistical Software (Wilkinson, 1990) was used for the adjustment of experimental data. Residue analysis and the following four standard quantitative parameters were applied to compare the accuracy of the adjustments: coefficient of determination $\left(\mathrm{R}^{2}\right)$, standard error of the parameter (ASE), standard error of the estimated value (SE) and the mean relative percentage of deviation $(\mathrm{P})$.

The heat of sorption of water in castor seeds $\left(\mathrm{L}_{\mathrm{b}}\right)$ was calculated by combining the best isotherm model with Clapeyron equation (Gely, 2003; Rohvein et al., 2004) obtaining the following expression:

$$
\mathrm{L}_{\mathrm{b}}=\mathrm{L}_{\mathrm{f}}+\frac{\mathrm{RT}^{2}}{\mathrm{M}_{\mathrm{v}}} \frac{\partial \ln \mathrm{a}_{\mathrm{w}}}{\partial \mathrm{T}}
$$

In addition $\mathrm{L}_{\mathrm{b}} / \mathrm{L}_{\mathrm{f}}$ was found by using Othmer method. From Clapeyron equation (Eq (5)):

$$
\frac{\partial \mathrm{P}_{\mathrm{s}}}{\partial \mathrm{T}}=\frac{\mathrm{L}_{\mathrm{f}} \mathrm{p}_{\mathrm{s}}}{\mathrm{RT}^{2}} \frac{\partial \mathrm{P}_{\mathrm{v}}}{\partial \mathrm{T}}=\frac{\mathrm{L}_{\mathrm{b}} \mathrm{p}_{\mathrm{v}}}{\mathrm{RT}^{2}}
$$

by assuming $\mathrm{L}_{\mathrm{b}} / \mathrm{L}_{\mathrm{f}}$ independent of temperature (Hunter, 1987), the integration of the equation obtained from the mathematical relation of equation 6 , gives:

$$
\ln \left(\mathrm{p}_{\mathrm{v}}\right)=\frac{\mathrm{L}_{\mathrm{b}}}{\mathrm{L}_{\mathrm{f}}} \ln \left(\mathrm{p}_{\mathrm{s}}\right)+\mathrm{D}
$$

Othmer (1940) showed that the ratio of $\mathrm{L}_{b} / \mathrm{L}_{\mathrm{f}}$ is the slope of the straight-line obtained by plotting (for a range of temperature) the log of the partial pressure of water vapor generated within a seed at a single moisture content against the equivalent saturated vapor pressure of water (Eq. (7)). The variation of the partial vapor pressure in the grain with the temperature can be calculated from the relationship between $\mathrm{RH}$ and $\mathrm{M}_{\mathrm{e}}$ given by equations of sorption isotherms (Nellist and Bruce, 1995).

Gallaher (1951) expressed the dependence of $\mathrm{L}_{\mathrm{b}} / \mathrm{L}_{\mathrm{f}}$ with moisture content through the following equation:

$\mathrm{L}_{\mathrm{b}}=\mathrm{L}_{\mathrm{f}}(1+\alpha \exp (\beta \mathrm{M}))$

\section{RESULTS AND DISCUSSION}

Initial moisture content of original castor seeds was $7.5 \%$ d.b. Oil contents of whole seeds and kernels resulted 55.5 and $72.3 \%$ (d.b.) respectively. Experimental data of sorption moisture for castor seeds are showed in Figure 1 (symbols). The isotherms show an increase of the equilibrium moisture content with water activity at constant temperature. At constant relative humidity, a decreasing of equilibrium moisture content with temperature was observed.

Table 1 shows the adjustment of the sorption isotherms evaluated through equations (1), (2) and (3). The statistics parameters obtained showed a reasonable adjustment for all models studied with similar values for the parameters $\mathrm{R}^{2}$ and $\mathrm{SE}$, although $\mathrm{P}$ parameter of modified Henderson equations resulted $11.4 \%$ lower than the corresponding parameter of modified Oswin equation and $47.67 \%$ lower than the same parameter of modified Halsey equation.

Table 2 shows the results of the adjustment of GAB equation (Eq. 4) for each temperature. The statistical parameters $\mathrm{R}^{2}, \mathrm{SE}$ and $\mathrm{P}$ suggest a good adjustment for temperature.

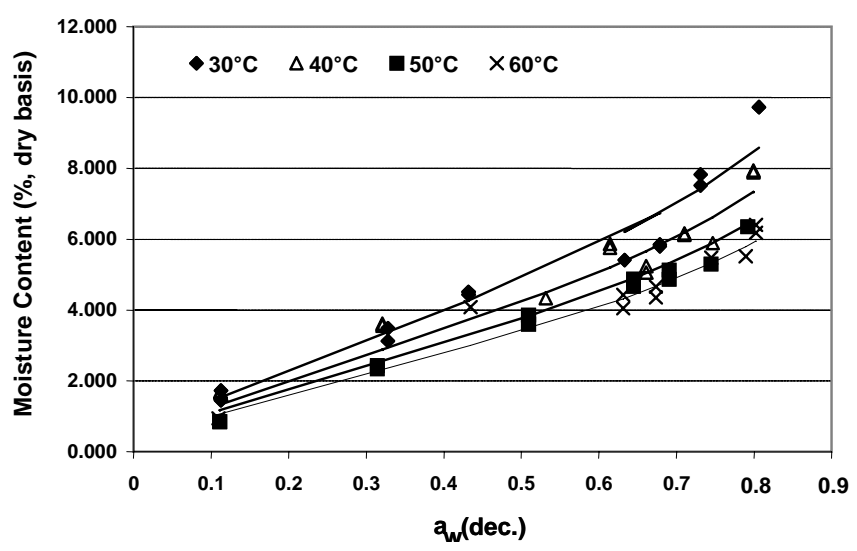

Figure 1: Desorption isotherms for castor seeds at 30, 4050 and $60^{\circ} \mathrm{C}$. Symbols represent experimental data and lines represent the modified Henderson equation. 
Table 1: Adjustment of modified Halsey, Oswin and Henderson models for castor seeds

\begin{tabular}{|l|c|c|c|c|c|c|}
\hline Model & A (ASE)* & B (ASE)* & C (ASE)* & R $^{2}$ & SE & P \\
Modified & $\begin{array}{r}1.5 \mathrm{E}-3 \\
(4 \mathrm{E}-21)\end{array}$ & $\begin{array}{r}1.52 \\
(0.06)\end{array}$ & $\begin{array}{r}11.31 \\
(5.36)\end{array}$ & 0.94 & 1.86 & 9.46 \\
\hline Menderson & $\begin{array}{r}2.68 \\
(0.18)\end{array}$ & $\begin{array}{r}-2.03 \mathrm{E}-2 \\
(2.3 \mathrm{E}-3)\end{array}$ & $\begin{array}{r}-0.62 \\
(2.86 \mathrm{E}-2)\end{array}$ & 0.94 & 1.95 & 13.97 \\
\hline Modified Halsey & $\begin{array}{r}6.02 \\
(0.23)\end{array}$ & $\begin{array}{r}-4.7 \mathrm{E}-2 \\
(4.7 \mathrm{E}-3)\end{array}$ & $\begin{array}{r}4.54 \mathrm{E}-1 \\
(2.1 \mathrm{E}-2)\end{array}$ & 0.95 & 1.79 & 10.54 \\
\hline
\end{tabular}

*Values into parenthesis indicate the standard error in the estimation of the corresponding parameter.

Table 2: Adjustment for temperature of GAB isotherm for castor seeds

\begin{tabular}{|l|l|l|l|l|l|l|}
\hline $\begin{array}{c}\text { Temperature } \\
\left({ }^{\circ} \mathbf{C}\right)\end{array}$ & A (ASE)* & B (ASE)* & C (ASE)* & $\mathbf{R}^{2}$ & SE & P \\
\hline 30 & $2.56(0.32)$ & $0.91(0.05)$ & $15.18(9.66)$ & 0.99 & 0.86 & 8.84 \\
40 & $2.90(0.46)$ & $0.79(0.08)$ & $14.55(8.43)$ & 0.99 & 0.94 & 8.21 \\
50 & $3.94(1.12)$ & $0.62(0.11)$ & $3.82(1.09)$ & 0.99 & 0.32 & 4.10 \\
60 & $2.82(0.86)$ & $0.71(0.13)$ & $8.24(6.10)$ & 0.99 & 0.71 & 9.34 \\
\hline
\end{tabular}

*Values into parenthesis indicate the standard error in the estimation of the corresponding parameter.

The analysis of the relationship between Gab's parameters and temperature shows that an increase in temperature from $30^{\circ} \mathrm{C}$ to $60^{\circ} \mathrm{C}$ causes an increase of $10 \%$ for A parameter, with an average value of $3.05 \pm 0.6$. For $\mathrm{B}$, the same change in temperature causes a decrease of $22.2 \%$ with an average value of $0.76 \pm 0.12$. This behavior shows a lower influence of the temperature on these two parameters when compared to the variation of $\mathrm{C}$ parameter that shows a decreasing of $45.7 \%$ with the increase of temperature. From these results, a modification of $\mathrm{GAB}$ equation including the $\mathrm{C}$ parameter temperature-dependent was proposed and showed in Equation (9). Table 3 shows the statistical results of this adjustment.

$$
M_{e}=\frac{A B \frac{C}{T} a_{w}}{\left(1-B a_{w}\right)\left(1-B a_{w}+B \frac{C}{T} a_{w}\right)}
$$

Despite the coefficient of determination being higher than the values obtained from the adjustments of equations (1), (2) and (3) from Table 1, the values of SE and $\mathrm{P}$ resulted $15 \%$ and $7.2 \%$ higher than the previous values obtained from the adjustment of Henderson modified equation.

The analysis of the residues of $\mathrm{M}_{e}$, calculated as the difference between experimental equilibrium moisture values and the predicted ones, showed an horizontal band rounding zero with no identification of a trend for any of the functionalities analyzed (Fig. 2). Normally the residues would show a horizontal band centered in zero with any behavior pattern (Chen and Morey, 1989).

Although the Eq. (1), (2) and (3) and (9) predicted reasonably the experimental values, modified Henderson equation showed in Fig. 1 indicated a lower valor of the mean relative percentage deviation $(\mathrm{P})$.

From the modified Henderson equation, the safe storage moisture content $\left(\mathrm{M}_{\mathrm{s}}\right)$ was evaluated for a water activity $\mathrm{a}_{\mathrm{w}}$ of 0.7 in a temperature range between 20 and $40^{\circ} \mathrm{C}$ (Fig 3). According to BarbosaCánovas et al. (2003) the value of 0.7 represents the moisture level at which the rate of fungi growth is minimum. The values obtained varied between 6.1 (for $40^{\circ} \mathrm{C}$ ) and $8.4 \%$ d.b. (for $20^{\circ} \mathrm{C}$ ). As can be observed, a temperature decrease of $20^{\circ} \mathrm{C}$ caused an increase of the safe storage moisture content of 38.22 $\%$.

The experimental values of the safe storage moisture content for castor seeds in the range of temperature evaluated showed lower values than those reported for other traditional oilseeds in the commercialization standard norms as e.g. sunflower $12.36 \%$ d.b. and rapeseed $9.3 \%$ d.b.

Table 3: Adjustment of GAB model modified in this work (Eq. 9) for castor seeds

\begin{tabular}{|c|r|r|r|r|}
\hline \multicolumn{2}{|c|}{ Parameter } & $\mathbf{R}^{2}$ & SE & P \\
\hline A & $7.75(1.52)$ & & & 10.19 \\
B & $0.44(0.07)$ & 0.98 & 2.19 & \\
\hline
\end{tabular}

*Values into parenthesis indicate the standard error in the estimation of the corresponding parameter. 


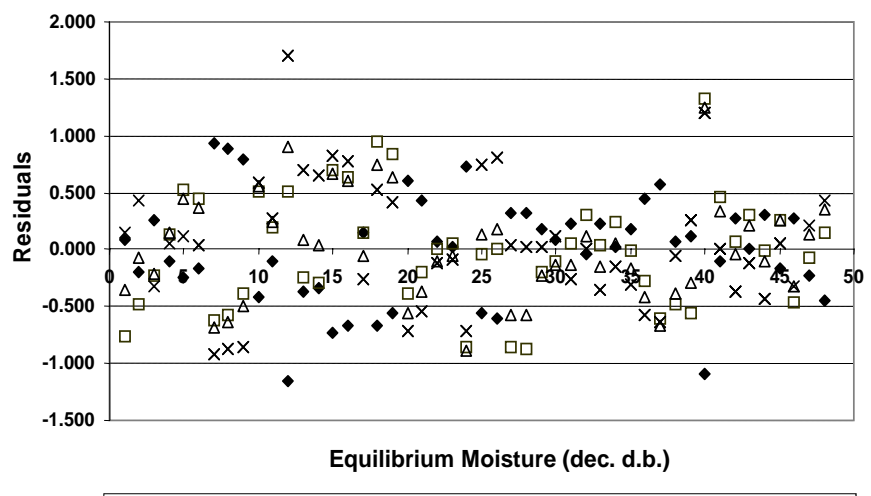

- HT Modified $\square$ Halsey Modified $\Delta$ Modified Oswin $\times$ GAB Modified in this work

Figure 2: Analysis of the residues of $\mathrm{M}_{\mathrm{e}}$ by using modified Henderson, Halsey, Oswin and GAB models.

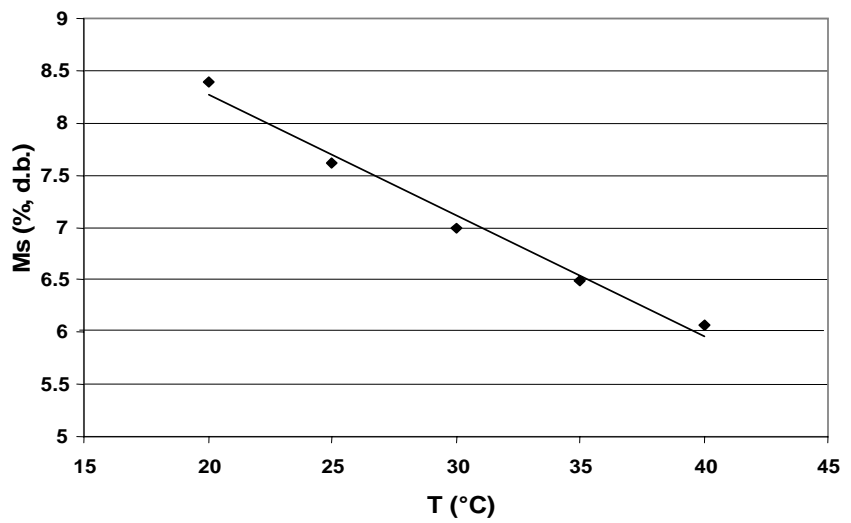

Figure 3: Variation of the safe storage moisture content $\left(\mathrm{M}_{\mathrm{s}}\right)$ with temperature.

Experimental (symbols) and predicted by equation 10 (line)

The variation of the safe storage moisture content with temperature showed a lineal trend (Eq. 10) with a determination coefficient $\mathrm{R}^{2}$ of 0.99

$$
\mathrm{M}_{\mathrm{s}}=-0.1155 \mathrm{~T}+10.58
$$

\section{Heat of Vaporization}

The heat of vaporization for castor seeds was evaluated at four temperatures in a range of moisture between 1 and $30 \%$ d.b. The behavior of $L_{b}$ resulted similar for all analyzed conditions decreasing with the increase of moisture and temperature and trending to the water heat of vaporization value at each corresponding temperature (Fig. 4). At $30^{\circ} \mathrm{C}$ a decrease of moisture content from higher values to $15 \%$ (d.b.) caused a light increase of $\mathrm{L}_{\mathrm{b}}$ from 2431.7 (coincident with $\mathrm{L}_{\mathrm{f}}$ at $30^{\circ} \mathrm{C}$ ) to $2531.6 \mathrm{~kJ} / \mathrm{kg}$ and represents an increment of $4.1 \%$. A decrease of moisture from $14.5 \%$ to $1 \%$ caused a deep change in $\mathrm{L}_{\mathrm{b}}$ to a final value of $3427.8 \mathrm{~kJ} / \mathrm{kg}$, which represents an increment of $35.4 \%$.

The vapor pressure of water in castor seeds against the vapor pressure of pure water in log-log graphic according the concept of Othmer (1940) was represented through equations (7) and (8) for a temperature range between 30 and $60^{\circ} \mathrm{C}$. Figure 5 represents the vapor pressure of castor seeds for moisture content of 1 and $8.5 \%$. From the slopes of the parallel lines obtained, the values of $\mathrm{L}_{\mathrm{b}} / \mathrm{L}_{\mathrm{f}}$ (Equation (11)) resulted 1.338 (for $1 \%$ m.c.) and 1.102 (for $8.5 \%$ m.c.).

$$
\begin{aligned}
& \ln \left(\mathrm{p}_{\mathrm{s}}\right)=1.338 \ln \left(\mathrm{p}_{\mathrm{v}}\right)-\left.5.6289\right|_{\mathrm{M}=1 \%} \\
& \ln \left(\mathrm{p}_{\mathrm{s}}\right)=1.1019 \ln \left(\mathrm{p}_{\mathrm{v}}\right)-\left.1.0621\right|_{\mathrm{M}=8.5 \%}
\end{aligned}
$$

The relationship between moisture content and $\mathrm{L}_{\mathrm{b}} / \mathrm{L}_{\mathrm{f}}$ (obtained from the Othmer relationship) represented in Fig. 6, showed values varying between 1.01 (for $14.5 \%$ d.b.) and 1.34 (for $1 \%$ d.b.). The adjusting of these values through Eq. (8) allowed obtaining the characteristic parameters for castor seeds, which are $\alpha=0.44(\mathrm{ASE}=0.022)$ and $\beta=-0.17 \quad(\mathrm{ASE}=0.012)$ with a determination coefficient $R^{2}$ of 0.97 . The form of Eq. (8) for castor seeds resulted:

$$
\mathrm{Lb} / \mathrm{Lf}=1+0.44 \times \exp (-0.17 \mathrm{M})
$$




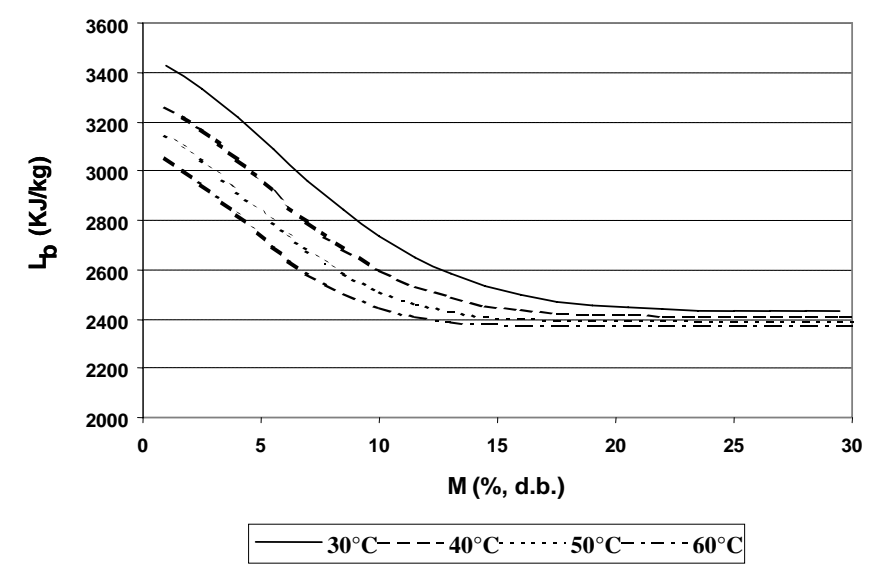

Figure 4: Variation of the heat of vaporization of water in castor seeds $\left(\mathrm{L}_{\mathrm{b}}\right)$ with moisture content for temperatures between $30^{\circ} \mathrm{C}$ and $60^{\circ} \mathrm{C}$.

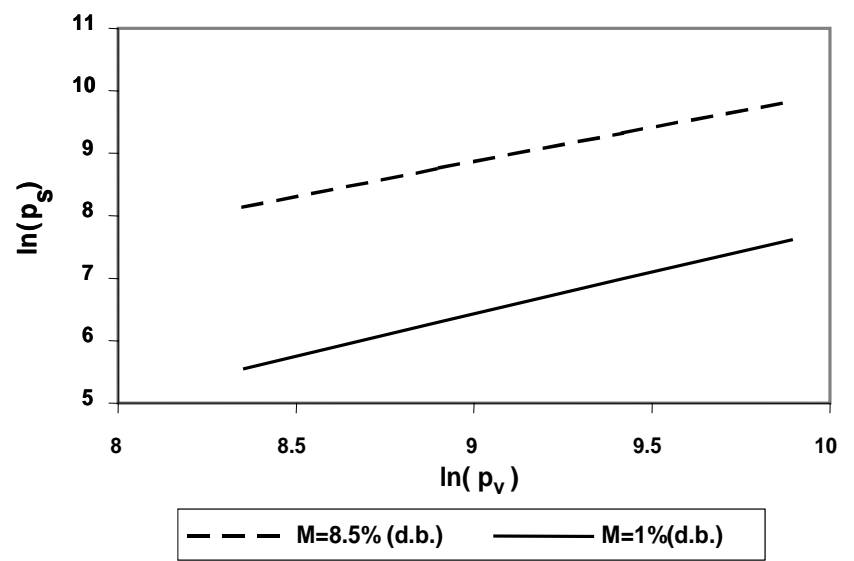

Figure 5: Othmer relationship for moisture content of 1 and 8.5\% d.b.

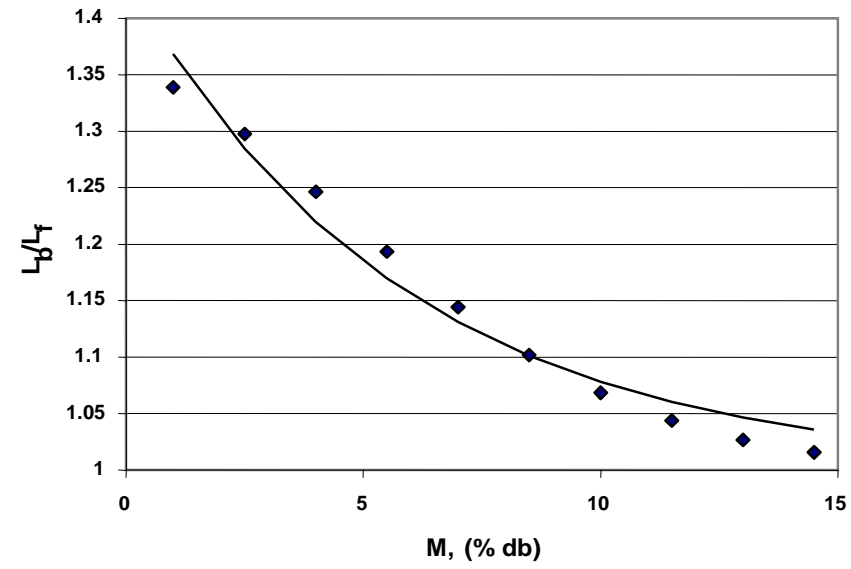

Figure 6: Relationship between the heat of vaporization of water in castor seeds and free water at different moisture contents. Values evaluated from Othmer (symbols) and from adjustment of Eq. 12 (lines). 


\section{CONCLUSIONS}

Experimental values of $\mathrm{M}_{\mathrm{e}}$ of castor seeds obtained from static gravimetric method were adjusted using modified Oswin, Halsey, Henderson and $\mathrm{GAB}$ equations. Modified Henderson resulted the best model to predict equilibrium moisture content for castor seeds with a determination coefficient higher than 0.94 .

The experimental values of the safe storage moisture content for castor seeds evaluated in the range of temperature between 30 and $60^{\circ} \mathrm{C}$ varied between 6.1 (for $40^{\circ} \mathrm{C}$ ) and $8.4 \%$ d.b. (for $20^{\circ} \mathrm{C}$ ), showing lower values than those reported for other traditional oilseeds.

The sorption heats evaluated from the combination of Clapeyron and modified Henderson equations varied between 3400 and $2373 \mathrm{~kJ} / \mathrm{k}$ for moisture contents between 1 and $28 \%$ (d.b.) respectively. Using Othmer relationship the ratio $\mathrm{L}_{\mathrm{b}} / \mathrm{L}_{\mathrm{f}}$ varied between 1.01 and 1.34 in the range of moisture content between 1 and $14.5 \%$ d.b. explained through an exponential relationship.

\section{NOMENCLATURE}

\begin{tabular}{|c|c|}
\hline$a_{w}$ & Water activity \\
\hline $\mathrm{A}, \mathrm{B}, \mathrm{C}$ & $\begin{array}{l}\text { Parameters of Equations } 1 \text {, } \\
2,3 \text { and } 4\end{array}$ \\
\hline d.b. & dry basis \\
\hline $\mathrm{D}$ & constant of integration \\
\hline ERH & $\begin{array}{l}\text { Equilibrium Relative } \\
\text { Humidity }\end{array}$ \\
\hline $\mathrm{L}_{\mathrm{b}}$ & $\begin{array}{l}\text { Heat of sorption of water in } \\
\text { the castor seeds }\end{array}$ \\
\hline $\mathrm{L}_{\mathrm{f}}$ & Heat of sorption of water \\
\hline M & Moisture content (m.c.) \\
\hline $\mathrm{M}_{\mathrm{e}}$ & $\begin{array}{l}\text { Equilibrium moisture } \\
\text { content }\end{array}$ \\
\hline $\mathrm{M}_{\mathrm{s}}$ & Safe moisture \\
\hline $\mathrm{M}_{\mathrm{v}}$ & Molecular weight of water \\
\hline $\mathrm{p}_{\mathrm{s}}$ & Saturation pressure of water \\
\hline $\mathrm{p}_{\mathrm{v}}$ & $\begin{array}{l}\text { Partial pressure of water } \\
\text { vapor }\end{array}$ \\
\hline $\mathrm{R}$ & constant universal of gases \\
\hline RH & Relative humidity \\
\hline $\mathrm{T}$ & Temperature \\
\hline$\alpha, \beta$ & Parameters of the Equation 8 \\
\hline
\end{tabular}

\section{Statistical Parameters}

$\begin{array}{ll}\text { ASE } & \begin{array}{l}\text { Standard error of the } \\ \text { parameter }\end{array} \\ \mathrm{P} & \begin{array}{l}\text { Mean relative percentage of } \\ \text { deviation }\end{array} \\ \mathrm{R}^{2} & \begin{array}{l}\text { Coefficient of determination } \\ \mathrm{SE}\end{array} \\ & \begin{array}{l}\text { Standard error of the } \\ \text { estimated value }\end{array}\end{array}$

\section{REFERENCES}

Aguerre R., Suarez C. and Viollaz P., The Temperature Dependence of Isosteric Heat of Sorption of Some Cereal Grains, International Journal of Food Science and Technology, 23, 141-145 (1988).

AOAC, Association of Official Analytical Chemists, Official Methods of Analysis, 13th Ed., Washington DC, (1980).

ASAE Standards, Standards Engineering Practices Data, American Society of Agricultural Engineers, 46th Ed. St. Joseph, MI (1999).

AOCS, Official Methods and Recommended Practices of the American Oil Chemists' Society, AOCS Press, Champaign, Illinois (1997).

Barbosa-Cánovas G. V.,Fernández-Molina J. J., Alzamora S. M., Tapia M. S., López Malo A.and Welti Chanes J., Handling and Preservation of Fruits and Vegetables by Combined Methods for Rural Areas (2003).

Brooker D., Bakker-Arkema F. and Hall C., Drying and Storage of Grains and Oilseeds, New York: Van Nostrand Reinhold (1992).

Chen, C. and Jayas, D., Evaluation of the GAB Equation for the Isotherms of Agricultural Products, American Society of Agricultural Engineers, 41(6), 1755-1760 (1998).

Cheng Chia, C. and Vance Morey, R., Comparison of Four EMC/ERH Equations, Transactions of the ASAE, 32 (3), 983-990 (1989).

Chirife, J. and Iglesias, H., Equations for Fitting Water Sorption Isotherms of Foods: Part 1 - a Review, Journal of Food Technology, 13, 159-174 (1978).

Falasca S., Bernabé M. and Ulberich A., Regional Impact in Semi-arid Zone of Argentina: Implanting Cultures for Biodiesel,

Gallaher, G., A Method of Determining the Latent 
Heat of Agricultural Crops, Agricultural Engineering, 32, 34-38 (1951).

Gely, M., Technical-Economic Feasibility of DryAeration of Soybean in Storage Plants, Thesis of Master, Facultad de Ingeniería, UNCPBA, Argentina (2003).

Hunter, A., An Isostere Equation for Same Common Seeds, Journal of Agricultural Engineering Research, 37, 93-105 (1987).

Nellist, M. E. and Bruce, D. M., Heated-air Grain Drying, In: Jayas, D. S., White N.D.G., Muir W.E. (Eds), Stored Grain Ecosystems. Marcel Dekker, Inc., pp. 309-658 (1995).

Othmer, D. F., Correlating Vapor Pressure and Latent Heat Data, Journal of Industrial and Engineering Chemistry, 32(6), 841-845 (1940).
Perry, R. and Chilton, C., Chemical Engineers' Handbook. $5^{\text {th }}$ ed. McGraw-Hill. New York (1991).

Rao, M. A. and Rizvi, S. S., Engineering Properties of Foods. Marcel Dekker (1994).

Rohvein C., Santalla E. and Gely M. C., Estimation of Sorption Isotherm and the Heat of Sorption of Quinoa (Chenopodium quinoa Willd.) Seeds, Food of Science \& Technology International, 10(6), 409-413 (2004).

Shatadal, P. and Jayas, D., Moisture Sorption Isotherms of Grain and Oilseeds, Postharvest News and Information, 1(6), 447-451 (1990).

Sun, D. W., Comparison and Selection of EMC/ERH Isotherm Equations for Rice, Journal of Stored Products Research, 35, 249-264 (1999).

Wilkinson, L., SYSTAT: The System for Statistics. Evanston. IL: SYSTAT Inc. (1990). 